GSA Data Repository 2016079

\title{
Morphological evolution of a new volcanic islet sustained by compound
}

\section{lava flows}

Fukashi Maeno*, Setsuya Nakada, and Takayuki Kaneko

Earthquake Research Institute, The University of Tokyo, 1-1-1 Yayoi, Bunkyo-ku, Tokyo 113-0032,

Japan

*E-mail: fmaeno@eri.u-tokyo.ac.jp; Tel: +81-3-5841-4779; Fax: +81-3-3812-6979

This supplementary file contains the following data and text.

- Figure DR1: TerraSAR-X images

- Figure DR2: Landsat-8 images

- Appendix DR1: Petrological characteristics and viscosity estimation with Table DR1 and Figure DR3

- Appendix DR2: Volume estimation with Figures DR4, DR5, and DR6

- Appendix DR3: Fractal analyses with Table DR2 and Figures DR7 and DR8 

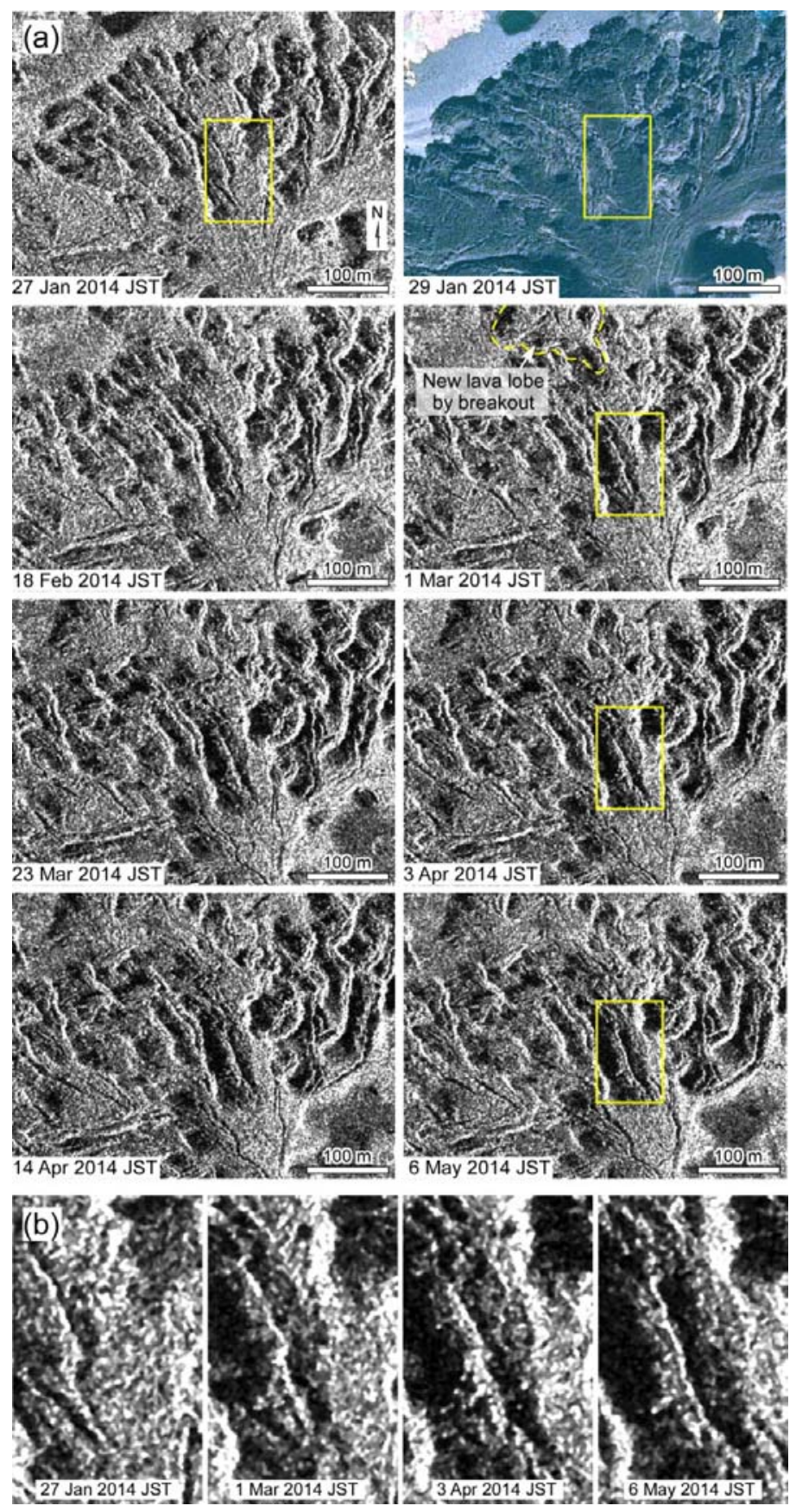

Figure DR1. (a) Lava lobes in the northern area with clefts, taken by TerraSAR-X (27 January to 6 May 2014, except upper right) and Pleiades optical satellite (29 January 2014, upper right). A new lava lobe generated by a breakout is indicated by the broken line in the upper part of the panel of 1 March 2014. Note the clefts (indicated by rectangles) that widen with time as shown in the magnifications in figure (b) (the width of each photo is about $80 \mathrm{~m}$ ). In aerial observations we confirmed that the cleft shapes are not open lava channels. TerraSAR-X image (C2014 DLR, Distribution Airbus DS/Infoterra GmbH, Sub-Distribution [PASCO]. 

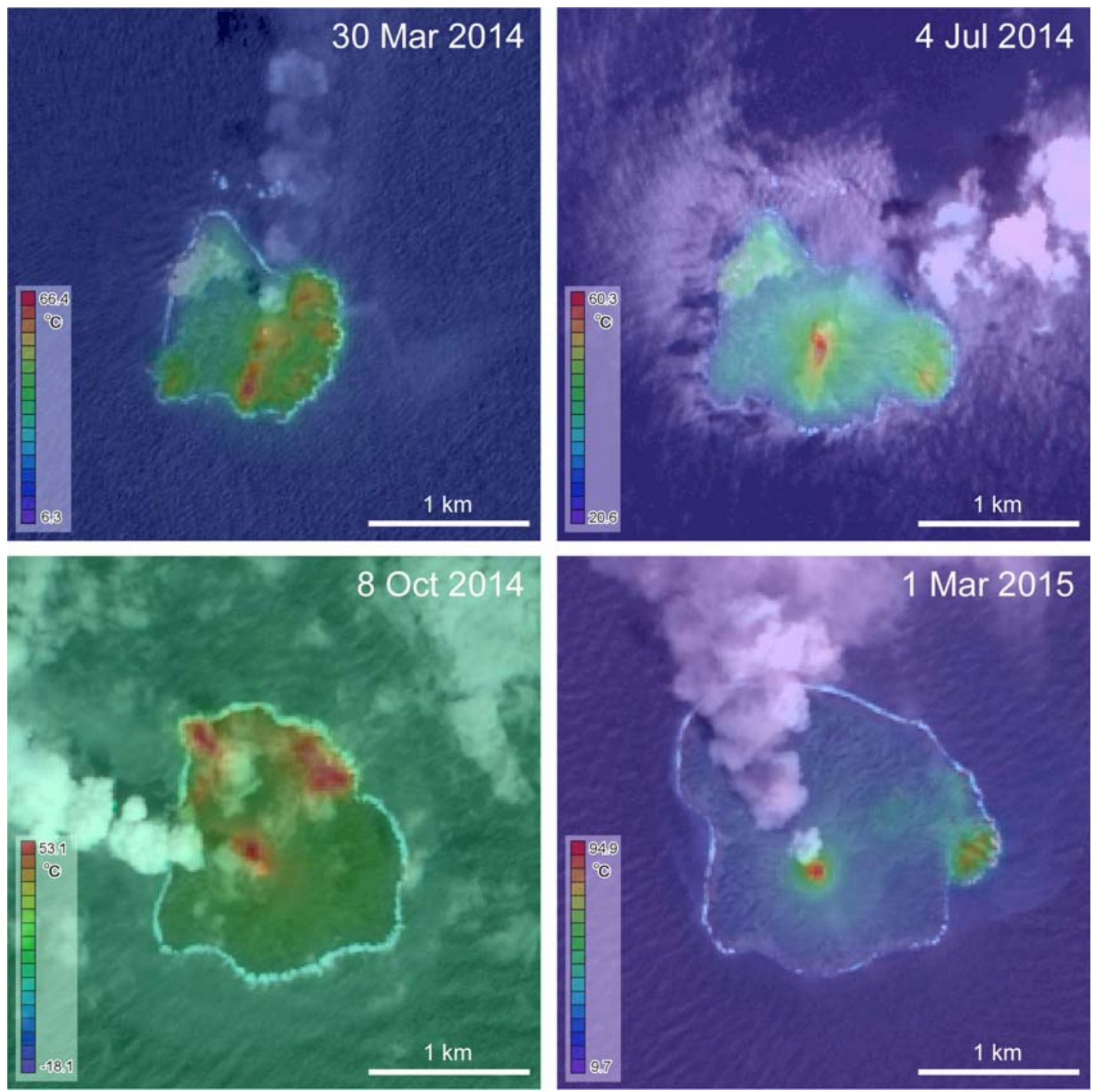

Figure DR2. Thermal infrared images of Nishinoshima, taken by Landsat-8 on 30 March 2014, 4 July 2014, 8 October 2014, and 1 March 2015. High-temperature areas are recognized at the center and on the flow margins. The images indicate that molten lava is transported via tubes beneath solidified crust to the flow front. The image taken on 1 March 2015 is consistent with our aerial observation of 4 March 2015 (Fig. 2e). The images were produced using Operational Land Imager data with multispectral bands of 30 meters and Thermal Infrared Sensor data with 100-m thermal bands. The source data were downloaded from AIST's LandBrowser (http://landbrowser.geogrid.org/landbrowser/). Landsat-8 data courtesy of the USGS. 


\section{Appendix DR1: Petrological characteristics and viscosity estimation}

Volcanic ash produced by the Strombolian activity at Nishinoshima was collected on board the $R / V$ Natsushima during the JAMSTEC NT15-E02 cruise on June 2015 (Tamura et al., 2015). It was analyzed with a microscope and an Electron Probe Micro-Analyzer (JXA-8800R) at Earthquake Research Institute, Univ. Tokyo. The data was used to estimate the temperature and viscosity of the erupted magma. The volcanic ash is composed of groundmass glass (50-70 vol.\%) and phenocrysts and microlite (plagioclase, clinopyroxene, orthopyroxene, and titanomagnetite; 30-50 vol.\%). Phenocrysts occupy $\sim 10$ vol.\%. The groundmass glass composition is $\sim 64.4$ wt.\% in $\mathrm{SiO}_{2}(\mathrm{Table}$ DR1). The bulk composition of the Nishinoshima lava flows is not known yet, but mass balance calculations using the modal and chemical compositions of the groundmass glass and crystals indicate that the petrological characteristics of the erupted magma are almost the same as those found in samples from the 1973-1974 eruption (58-59 wt.\% in $\mathrm{SiO}_{2}$ with 10 vol.\% phenocrysts; Umino and Nakano, 2007). Applying clinopyroxene and clinopyroxene-liquid thermometers (Putirka, 2008) to microlite crystals (pigeonite), the temperature of erupting magma was estimated as $1060-1090^{\circ} \mathrm{C}$ $(\mathrm{n}=35)$. We also applied the method proposed by Ishii (1975) and obtained a similar temperature $\left(\sim 1090^{\circ} \mathrm{C}\right)$. Saito et al. (2014) estimated a temperature range of $1060-1070^{\circ} \mathrm{C}$ from samples obtained by a fisherman near Nishinoshima, using a two-pyroxene thermometer.

Table DR 1. Groundmass glass and clinopyroxene compositions for Nishinoshima ash

\begin{tabular}{cccccc}
\hline & \multicolumn{3}{c}{ Groundmass glass } & \multicolumn{3}{c}{ Clinopyroxene } \\
\hline & Wt.\% & Stdv. & & Wt.\% & Stdv. \\
\hline $\mathrm{SiO}_{2}$ & 64.38 & $(0.56)$ & $\mathrm{SiO}_{2}$ & 52.98 & $(0.84)$ \\
$\mathrm{TiO}_{2}$ & 1.26 & $(0.07)$ & $\mathrm{TiO}_{2}$ & 0.44 & $(0.15)$ \\
$\mathrm{Al}_{2} \mathrm{O}_{3}$ & 13.20 & $(0.37)$ & $\mathrm{Al}_{2} \mathrm{O}_{3}$ & 1.68 & $(0.58)$ \\
$\mathrm{FeO}$ & 9.57 & $(0.30)$ & $\mathrm{FeO}$ & 19.63 & $(1.92)$ \\
$\mathrm{MnO}$ & 0.23 & $(0.04)$ & $\mathrm{MnO}$ & 0.67 & $(0.06)$ \\
$\mathrm{MgO}$ & 1.49 & $(0.18)$ & $\mathrm{MgO}$ & 18.54 & $(1.76)$ \\
$\mathrm{CaO}$ & 4.69 & $(0.18)$ & $\mathrm{CaO}$ & 5.93 & $(3.01)$ \\
$\mathrm{Na} 2 \mathrm{O}$ & 3.08 & $(0.34)$ & $\mathrm{Na}_{2} \mathrm{O}$ & 0.13 & $(0.06)$ \\
$\mathrm{K}_{2} \mathrm{O}$ & 1.56 & $(0.12)$ & $\mathrm{Cr}_{2} \mathrm{O}_{3}$ & 0.01 & $(0.01)$ \\
$\mathrm{P}_{2} \mathrm{O}_{5}$ & 0.55 & $(0.06)$ & & & \\
\hline $\mathrm{Total}^{2}$ & 100.00 & $\mathrm{n}=51$ & $\mathrm{Total}^{2}$ & 100.00 & $\mathrm{n}=35$ \\
\hline
\end{tabular}

Analyzed with a JXA-8800R Electron Probe Micro-Analyzer at the Earthquake Research Institute, The University of Tokyo, using an acceleration voltage of $15 \mathrm{kV}$ and a beam current of $12 \mathrm{nA}$. The beam diameter was set as $10 \mu \mathrm{m}$. The total values are normalized to $100 \mathrm{wt} . \%$. 
Using the groundmass glass composition and assumed water content, the relationship between the melt viscosity $\left(\eta_{m}\right)$ and temperature $(T)$ was calculated using the method of Giordano et al. (2006). The effect of crystallinity on the viscosity was also considered using the Einstein-Roscoe equation that describes the apparent viscosity of magma $\left(\eta_{a}\right)$ as $\eta_{a}=\eta_{m}(1-X / 0.6)^{-2.5}$, where $X$ is the crystallinity of magma (Marsh, 1981). There are no data for the water content of the lava flows in Nishinoshima. Here we assumed $0.0-1.5$ wt.\% in $\mathrm{H}_{2} \mathrm{O}$ for the erupted lavas, because the water content in the groundmass of extruded lavas tends to decrease toward 0 wt.\% in atmospheric pressure conditions according to the water solubility curve (e.g., $0.3 \mathrm{wt} \%$ for Shinmoedake andesite lava, Sato et al., 2013) and the water content of the Nishinoshima magma does not likely exceed 1.52.0 wt.\%. This is based on the estimate of Saito et al. (2014) of 1.7 wt.\% in $\mathrm{H}_{2} \mathrm{O}$, in a study that analyzed the melt inclusions in phenocrysts that indicated the magma chamber condition. As a result, the apparent viscosity is estimated to be in the order of $10^{4}$ Pas or more, where the maximum temperature was assumed as $\sim 1090^{\circ} \mathrm{C}$ based on the above temperature estimate (Fig. DR3).

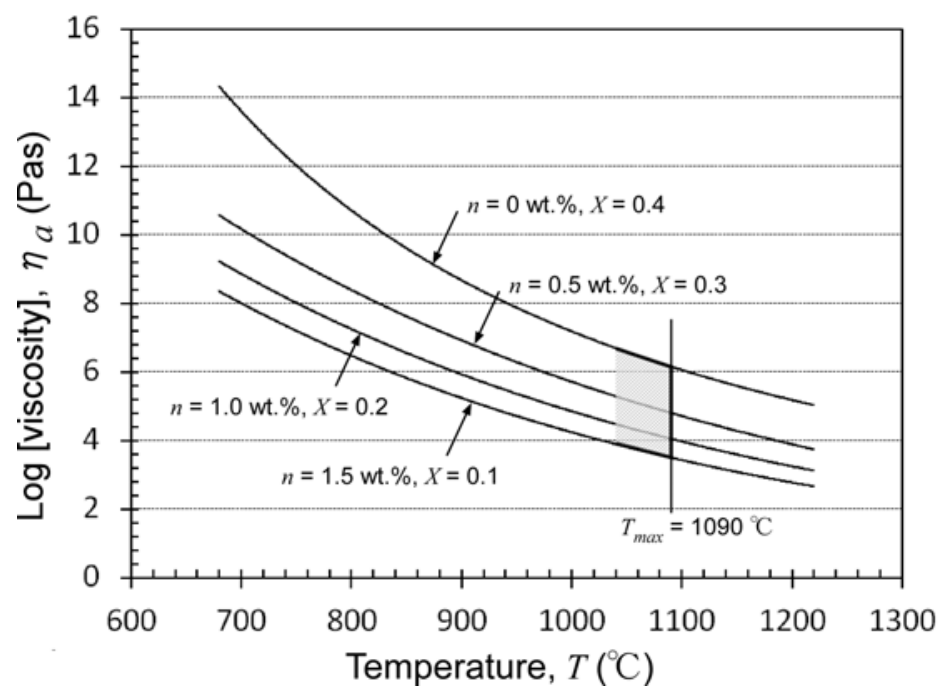

Figure DR3. Relationship between temperature $(T)$ and apparent viscosity $\left(\eta_{a}\right)$, using the groundmass glass composition, assumed water content $(n=0.0-1.5$ wt.\%), and crystallinity $(X=10-40$ vol.\%). The viscosity range for the same temperature is estimated for $n=0.0 \mathrm{wt} \%, X=0.4(\max$.$) and n=$ 1.5 wt. $\%, X=0.1$ (min.). $T_{\max }$ and the shaded area indicate the possible maximum temperature and range for Nishinoshima magma. 


\section{REFERENCES CITED}

Giordano, D, Russell, J.K., and Dingwell, D.B., 2008, Viscosity of magmatic liquids: a model: Earth and Planetary Science Letters, vol. 271, p. 123-134.

Ishii, T., 1975, The relations between temperature and composition of pigeonite in some lavas and their application to geothermometry: Mineralogical Journal, vol. 8, no. 1, p. 48-57.

Marsh, B., 1981, On the crystallinity, probability of occurrence, and rheology of lava and magma: Contribution to Mineralogy and Petrology, vol. 78, p. 85-98.

Putirka, K.D., 2008, Thermometers and barometers for volcanic systems: Reviews in Mineralogy and Geochemistry, vol. 69, p. 61-120.

Saito, G., Nakano, S., Geshi, N., Shinohara, H., Tomiya, A., and Miyagi, I., 2014, Petrologic characteristics of magma and degassed-magma volume of 2014 eruptions at Nishinoshima volcano: Volcanological Society of Japan, 2014 Fall Meeting, P2-07, in Japanese.

Sato, H., Suzuki-Kamata, K., Sato, E., Sano, K., Wada, K., and Imura, R., 2013, Viscosity of andesitic lava and its implications for possible drain-back processes in the 2011 eruption of the Shinmoedake volcano, Japan: Earth Planets and Space, vol. 65, p. 623-631.

Tamura, Y., Ishizuka, O., Maeno, F., Momma, H., Nichols, A., Sato, T., Furuyama, H., Koyama, Y., and Takano, K., 2015, NATSUSHIMA NT15-E02 Cruise Report: Japan Agency for Marine-Earth Science and Technology (JAMSTEC) Document Catalog, p. 56, http://www.godac.jamstec.go.jp/catalog/doc_catalog/metadataDisp/NT15-E02_all?lang=en

Umino, S., and Nakano, S., 2007, Geology of the Chichijima Retto District, Quadrangle Series, 1:50,000: Geological Survey of Japan, AIST, p. 71, in Japanese with English abstract. 


\section{Appendix DR2: Volume estimation}

The volume of erupted material and its temporal variation are estimated based on images showing the change of the outline of the new islet taken by TerraSAR-X, aerial observations, topography data of the new islet taken by an unmanned aerial vehicle operated by the Geospatial Information Authority of Japan (GSI, 2015), and pre-eruption bathymetry data taken by the Japan Coast Guard (JCG, 1993).

The volume above sea level ( $\left.V_{\text {land }}\right)$ at each point in time was calculated using the area, average thickness of the lava flow field and the shape of the scoria cone estimated based on TerraSAR-X data and aerial observations. GSI topography data (1.0 or $2.5 \mathrm{~m}$ DEM, horizontal resolution; $<1.0 \mathrm{~m}$ vertical resolution) is useful to confirm the estimation and minimize the error, but measurements by GSI were infrequent (6 times a year, Fig. DR4). Therefore, we primarily used TerraSAR-X data (a total of 28 images) and compared to GSI data, then estimated the variation of $V_{\text {land }}$. $V_{\text {land }}$ can be divided into the scoria cone part and the lava field part. Growth curves of the scoria cone height and average lava flow thickness are shown in Fig. DR4, in which a $\pm 5 \%$ error caused by the area estimation using TerraSAR-X images was considered.

The volume below sea level ( $\left.V_{\text {sea }}\right)$ at each point in time was calculated by comparing the extent of the new islet determined from TerraSAR-X and pre-eruption bathymetry data (JCG, 1993) (Fig. DR5). The contour interval for the bathymetry data is $5-10 \mathrm{~m}$ and the horizontal resolution is approximately $10-50 \mathrm{~m}$. We used the following procedure: (1) the extent of the new islet was traced based on the TerraSAR-X image and the area surrounded by the outline was divided into multiple segments having different sea depths at 5-10-m intervals; (2) the volume for each segment was then calculated by multiplying the segment area by the sea depth where a \pm 5 -m error (caused by the area estimation using TerraSAR-X images and the accuracy of the bathymetry data) was considered; (3) $V_{\text {sea }}$ was calculated by integrating all the segments.

The total volume $\left(V_{\mathrm{t}}\right)$ of the erupted material was calculated from $V_{\text {land }}+V_{\text {sea, }}$, where a 15-20\%

error, resulting from the accumulation of the estimation errors for both $V_{\text {land }}$ and $V_{\text {sea, }}$ was contained (Fig. DR6). The average discharge was calculated from the change of the total volume $\left(V_{\mathrm{t}}\right)$ every 11 or 22 days. Generally, the volume and discharge are dominated by the lava-flow field. The volume of the scoria cone is approximately $<10 \%$ of the lava-flow field, except during the initial stage of island 
formation. We also assumed that ashfall from Strombolian activity has little effect on the volume of the new island.
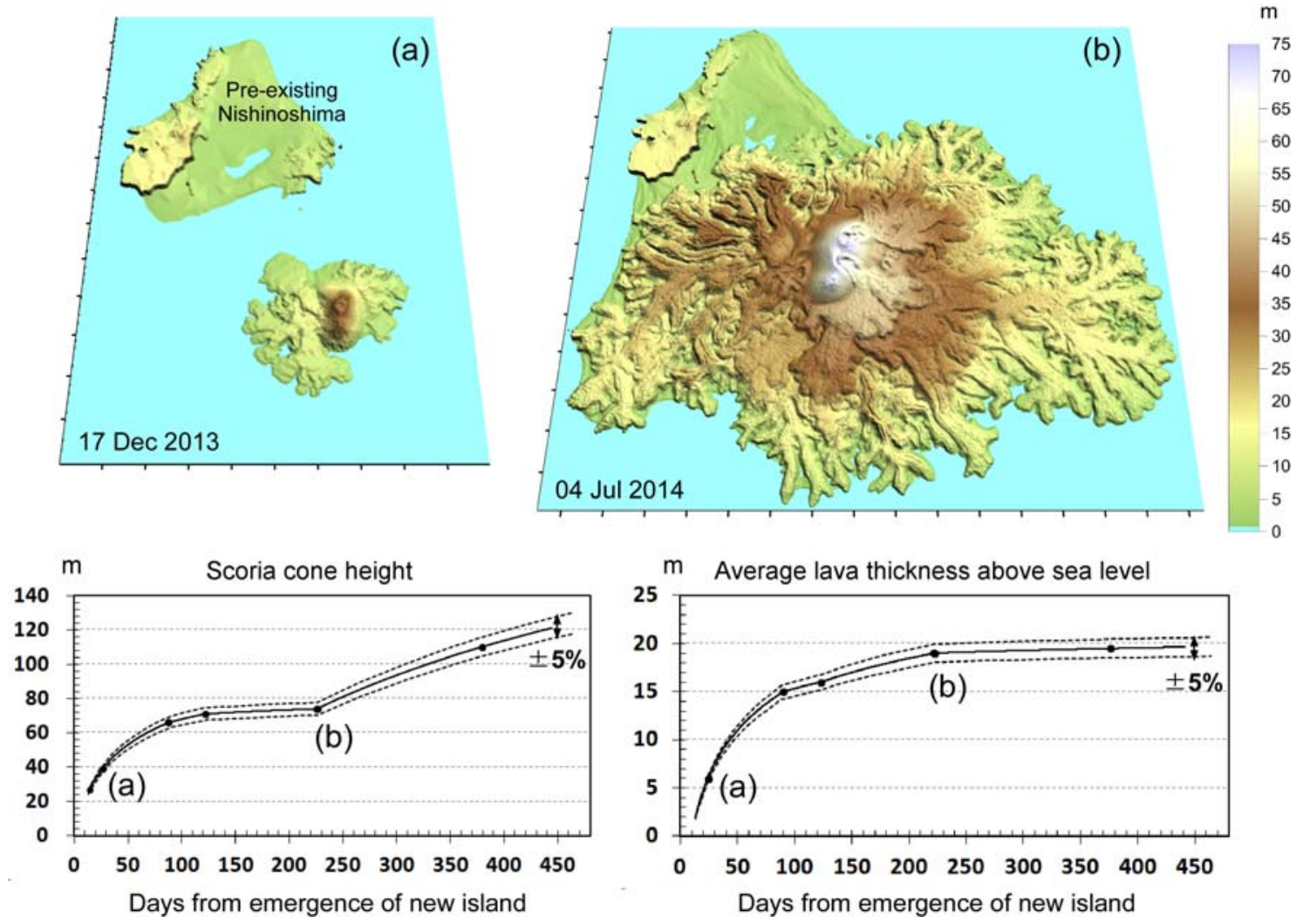

Figure DR4. (Upper panels) Topographic maps produced using DEM data provided by the Geospatial Information Authority of Japan (2015). (a) 17 Dec 2013, 2.5 m DEM; (b) 4 July 2014, 1.0 m DEM. The axes are marked at 100-m intervals. (Bottom panels) Growth curves of the scoria cone height and average lava thickness above sea level. Closed circles indicate estimates using GSI topography data. (a) and (b) mark the dates of the corresponding topographic maps shown above. These curves were used to calculate the variation of the volume above sea level. 


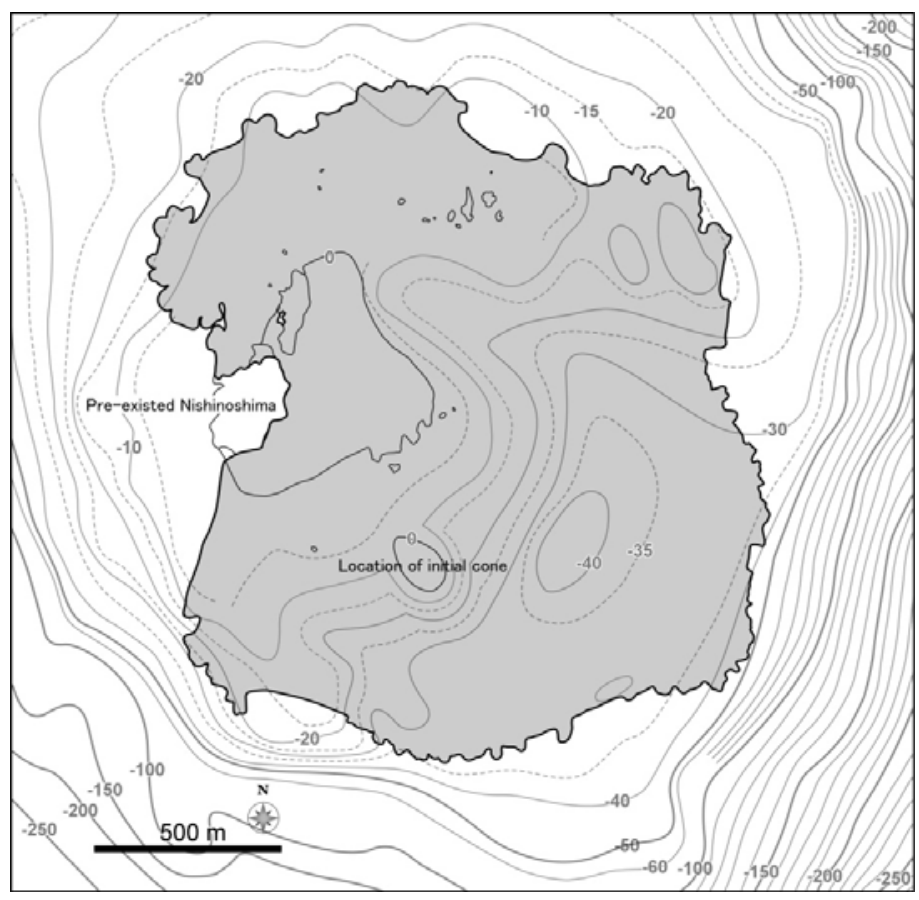

Figure DR5. Bathymetry map around Nishinoshima, before the 2013-2015 eruption. An outline of the new islet on 20 November 2014 is shown as an example. The approximate volume below sea level is estimated from the difference in the topography before and after the eruption. 


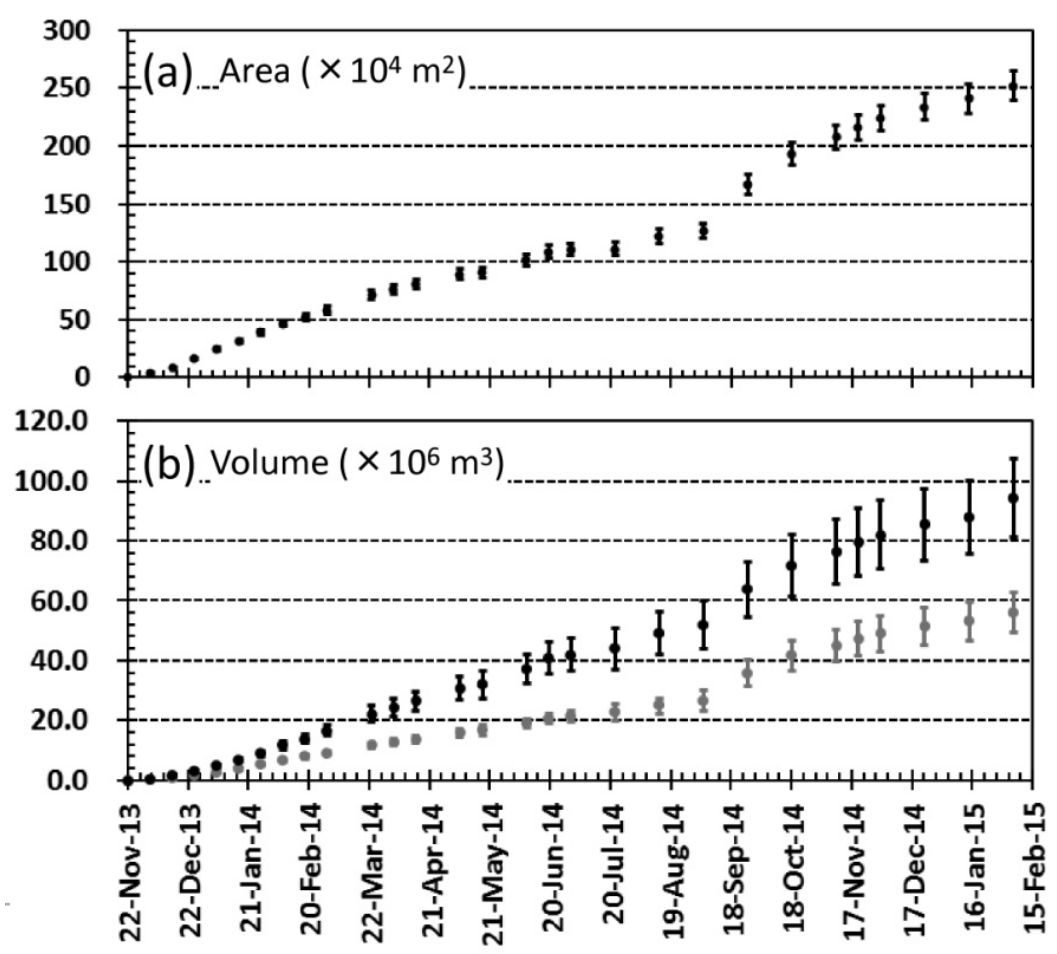

Figure DR6. Temporal variations of (a) area and (b) volume of the newly formed part of the island.

Black dots and error bars in (b) show the total volume; gray ones represent the data above sea level.

\section{REFERENCES CITED}

Geospatial Information Authority of Japan, 2015, Aerial photographs had taken around Nishinoshima Island, http://www.gsi.go.jp/kokusaikoryu/kokusaikoryu-e30056.html.

Japan Coast Guard, 1993, Basic map of the sea in coastal waters $(1 / 50,000)$, Nishinoshima, submarine structural chart and report of survey, p. 47. 


\section{Appendix DR3: Image processing procedures}

For the fractal analyses, we drew the outlines of the new lava flows based on TerraSAR-X images. The margin of the flow lobes was clearly identified in both the SAR and optical satellite images with a spatial resolution of a few meters (Fig. DR1). Although small-scale features cannot be captured, this resolution enables to trace the outlines of the lava flows. We did not include the pre-existing island and sandbars generated by secondary processes. Therefore, the outlines are not identical to the actual coastline. Flow lobes eroded by waves are included but they are minor.

We generated 8-bit binary images of lava flows with $2977 \times 3173$ pixels for each snapshot (Fig. DR7). We then found the edge of the object for each figure, using image-processing software (ImageJ $1.48 \mathrm{v}$ ). The thickness of the edge line is 1 pixel. Finally, we applied a box-counting method (Smith et al., 1996) where sets of square boxes (i.e., grids) are used to cover the boundary of the object and each set is characterized by a box size. The number of boxes required to cover the border is noted as a function of the box size. The log of the number of covering boxes of each size is plotted against the log of the length of the box edge (Fig. DR8). The straight-line result and fractal dimension are calculated. We used box sizes with $2^{n}$ pixels, where $n$ was set as 2 to $12(2.5-2600 \mathrm{~m}$ in actual scale) as shown in Table DR2.

Care was taken to select box sizes sufficiently large so as to exceed the spatial resolution of the images. The minimum box size was set at 4 pixels $\left(2.5 \mathrm{~m}, n_{\min }=2\right)$. The maximum box size was changed depending on the size of the object; this was determined based on the relationship between the number of covering boxes and $\mathrm{R}^{2}$ (determination coefficient). Here we examined two cases. For the first case, the maximum box size with $2^{n}\left(n=n_{\max }\right)$ was defined as the box size having both the least number of covering boxes exceeding one and $\mathrm{R}^{2}$ exceeding 0.995 , below which $\mathrm{R}^{2}$ begins to decrease rapidly. The fractal dimension calculated via this procedure was defined as $D_{1}$. For the second case, we found the fractal dimension using the maximum box size with $2^{n}\left(n=n_{\max }-\right.$ 1 ), in which $\mathrm{R}^{2}$ is generally much closer to 1.000 than that for $n=n_{\max }$. This fractal dimension is less than $D_{1}$ in general and defined as $D_{2}$. The possible ranges of fractal dimension derived from the two cases with $D_{1}$ and $D_{2}$ are shown in Fig. 3c. 

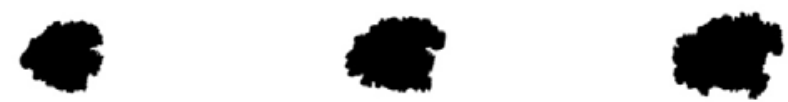

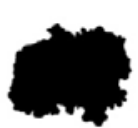

18 Feb 2014

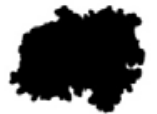

1 Mar 2014

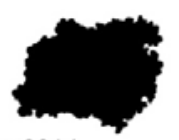

23 Mar 2014

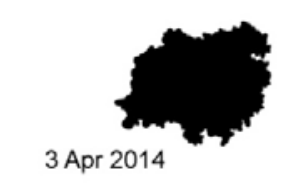

3 Apr 2014

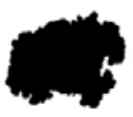

$\mathrm{Feb} 2014$

8 Jun 2014
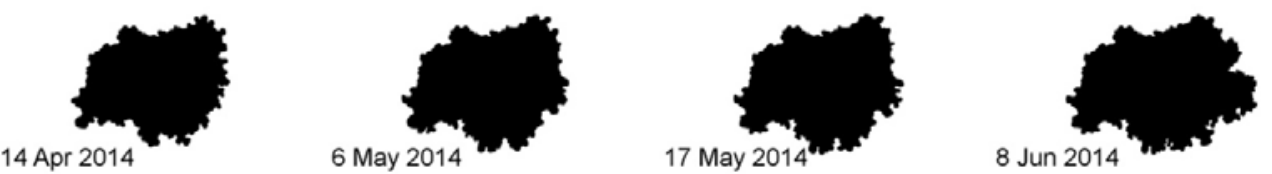

19 Jun 2014
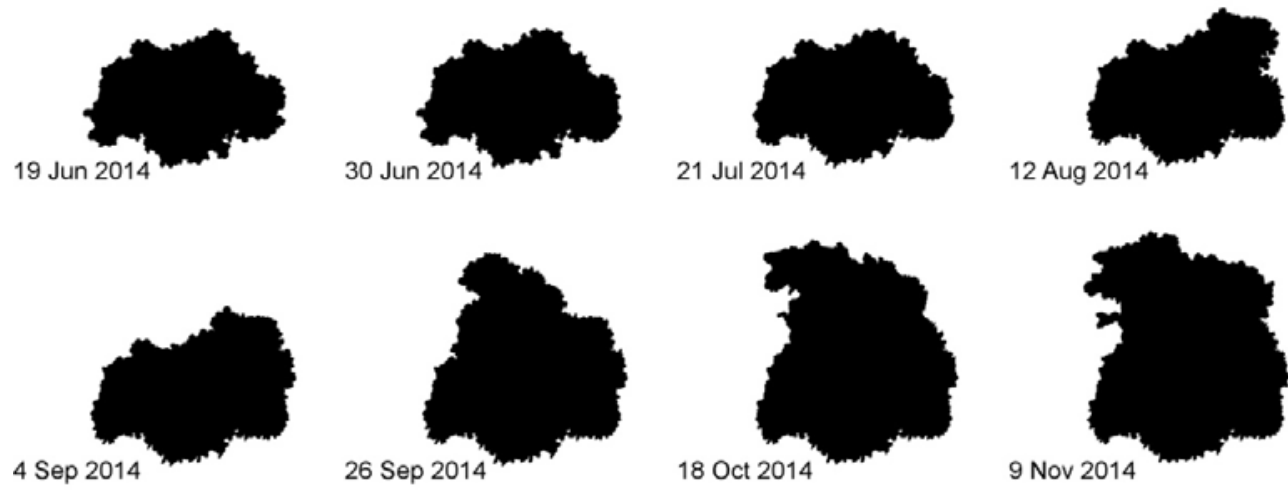

9 Nov 2014
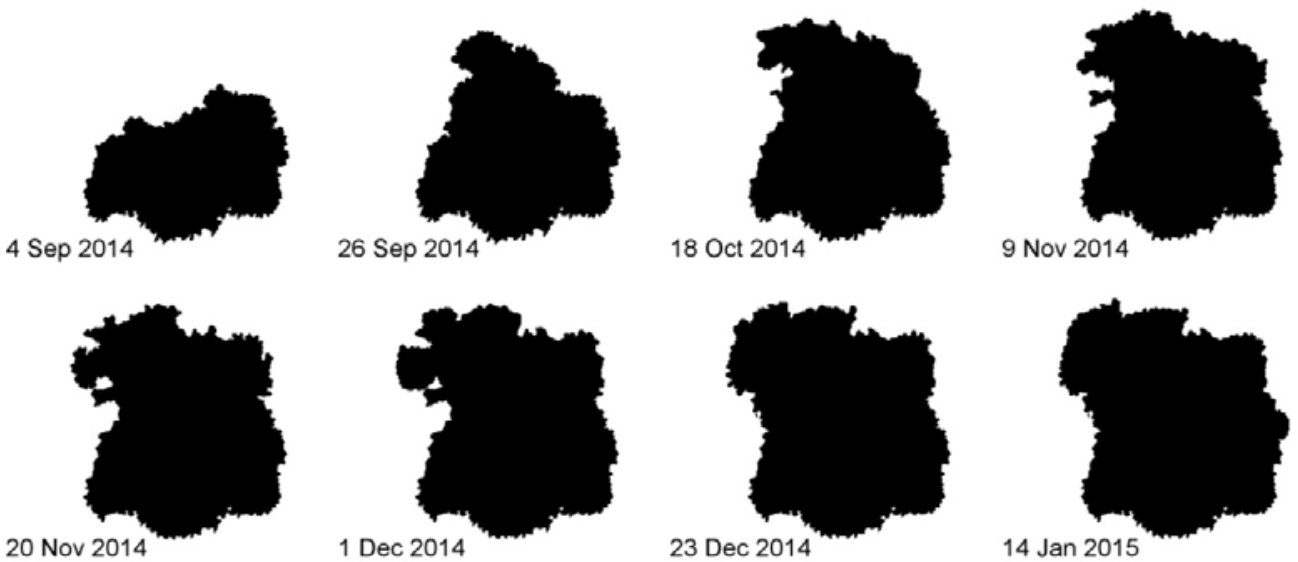

14 Jan 2015

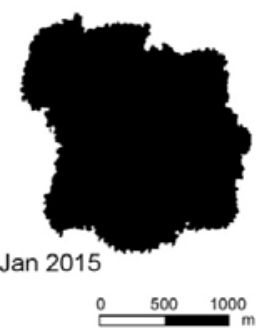

Figure DR7. Images used for fractal analyses. 


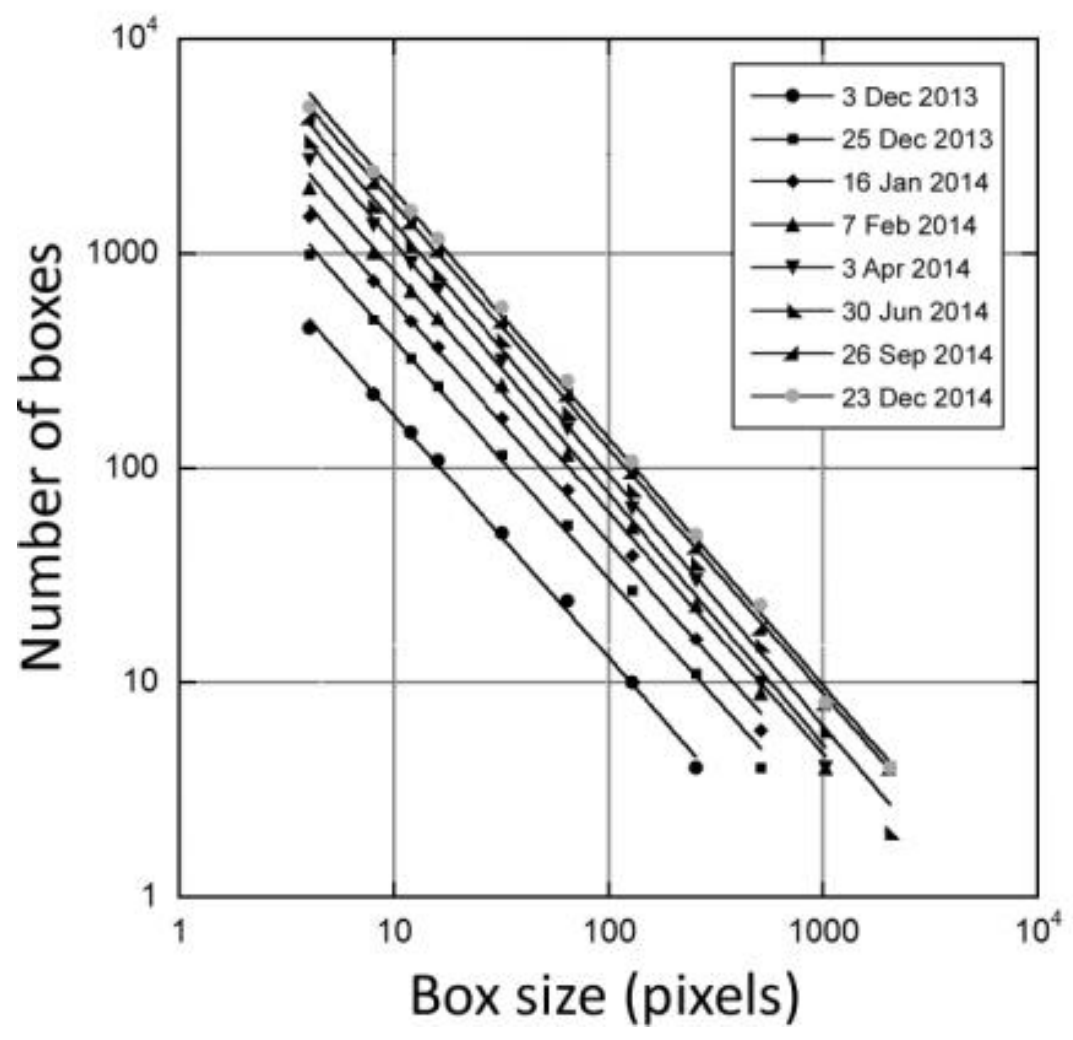

Figure DR8. Relationship between the number of boxes required to cover the border of each image and the box size in pixels. 
Table DR2 Box sizes $\left(2^{n}\right)$, fractal dimension, and determination coefficients

\begin{tabular}{|c|c|c|c|c|c|c|c|}
\hline & Date & $\mathrm{n}_{\min }$ & $\mathrm{n}_{\max }$ & $D_{1}$ & $\mathrm{R}^{2}$ & $D_{2}$ & $\mathrm{R}^{2}$ \\
\hline 1 & $2013 / 11 / 22$ & 2 & 6 & 1.048 & 0.9995 & 1.027 & 0.9999 \\
\hline 2 & $2013 / 12 / 3$ & 2 & 8 & 1.129 & 0.9977 & 1.093 & 0.9987 \\
\hline 3 & $2013 / 12 / 14$ & 2 & 9 & 1.126 & 0.9996 & 1.095 & 0.9996 \\
\hline 4 & $2013 / 12 / 25$ & 2 & 9 & 1.116 & 0.9966 & 1.073 & 0.999 \\
\hline 5 & $2014 / 1 / 5$ & 2 & 9 & 1.169 & 0.9963 & 1.124 & 0.9985 \\
\hline 6 & $2014 / 1 / 16$ & 2 & 9 & 1.123 & 0.9974 & 1.086 & 0.9991 \\
\hline 7 & $2014 / 1 / 27$ & 2 & 10 & 1.094 & 0.9997 & 1.086 & 0.9997 \\
\hline 8 & $2014 / 2 / 7$ & 2 & 10 & 1.126 & 0.9978 & 1.107 & 0.9977 \\
\hline 9 & $2014 / 2 / 18$ & 2 & 10 & 1.125 & 0.9984 & 1.111 & 0.9982 \\
\hline 10 & $2014 / 3 / 1$ & 2 & 10 & 1.139 & 0.9970 & 1.107 & 0.9983 \\
\hline 11 & $2014 / 3 / 23$ & 2 & 10 & 1.167 & 0.9969 & 1.141 & 0.9971 \\
\hline 12 & $2014 / 4 / 3$ & 2 & 10 & 1.170 & 0.9956 & 1.136 & 0.9961 \\
\hline 13 & $2014 / 4 / 14$ & 2 & 10 & 1.159 & 0.9951 & 1.113 & 0.9978 \\
\hline 14 & $2014 / 5 / 6$ & 2 & 10 & 1.165 & 0.9947 & 1.120 & 0.9971 \\
\hline 15 & $2014 / 5 / 17$ & 2 & 11 & 1.173 & 0.9968 & 1.147 & 0.9972 \\
\hline 16 & $2014 / 6 / 8$ & 2 & 11 & 1.177 & 0.9960 & 1.140 & 0.998 \\
\hline 17 & $2014 / 6 / 19$ & 2 & 11 & 1.169 & 0.9966 & 1.134 & 0.9984 \\
\hline 18 & $2014 / 6 / 30$ & 2 & 11 & 1.172 & 0.9965 & 1.137 & 0.9983 \\
\hline 19 & $2014 / 7 / 22$ & 2 & 11 & 1.169 & 0.9968 & 1.134 & 0.9986 \\
\hline 20 & $2014 / 8 / 13$ & 2 & 11 & 1.191 & 0.9962 & 1.154 & 0.9982 \\
\hline 21 & $2014 / 9 / 4$ & 2 & 11 & 1.185 & 0.9963 & 1.149 & 0.9983 \\
\hline 22 & $2014 / 9 / 26$ & 2 & 11 & 1.142 & 0.9993 & 1.144 & 0.9991 \\
\hline 23 & $2014 / 10 / 18$ & 2 & 11 & 1.143 & 0.9988 & 1.138 & 0.9983 \\
\hline 24 & $2014 / 11 / 9$ & 2 & 11 & 1.160 & 0.9987 & 1.160 & 0.9982 \\
\hline 25 & $2014 / 11 / 20$ & 2 & 11 & 1.166 & 0.9980 & 1.157 & 0.9974 \\
\hline 26 & $2014 / 12 / 1$ & 2 & 11 & 1.154 & 0.9976 & 1.142 & 0.997 \\
\hline 27 & $2014 / 12 / 23$ & 2 & 11 & 1.152 & 0.9985 & 1.145 & 0.998 \\
\hline 28 & $2015 / 1 / 14$ & 2 & 11 & 1.147 & 0.9984 & 1.140 & 0.998 \\
\hline
\end{tabular}

\section{REFERENCES CITED}

Smith, T.G., Lange, G.D., and Marks, W.B., 1996, Fractal methods and results in cellular morphology - dimensions, lacunarity and multifractals, Journal of Neuroscience Methods, v. 69, p. $123-136$. 